\title{
Evolution Procedure for Financial Stability of the Enterprises of Housing and Utilities Infrastructure
}

\author{
Varvara Dikareva, ${ }^{1, *}$ and Vadim S. Kankhva ${ }^{1}$ \\ ${ }^{1}$ Moscow State University of Civil Engineering,26, Yaroslavskoye shosse, Moscow,129337, Russia
}

\begin{abstract}
This article describes methods of assessment of the extent of the financial security of the enterprises of housing and utilities infrastructure. Resources, which can cover different groups of risks which appear in the process of activity of enterprises of housing and utilities infrastructure were structured in a particular way. Assessing valuation model was developed and intervals for determination of the type of financial security with graphical interpretation of the obtained data were defined on the basis of financial reporting. The degree of financial stability of companies for particular period of time can be assessed with the help of this method.
\end{abstract}

\section{Introduction}

Expedience of regulation of the economic security of the housing and utilities infrastructure enterprises is determined both by necessity to mitigate the negative impacts of the market environment and by the necessity to stimulate its increase. Provision of the steady functioning and development of the housing and utilities infrastructure enterprises firstly requires development of science-based techniques of assessment of the level of its economic security, definition indicators system, which can help to perform a factor analysis of security and manage the process of its increasing.

Variety of factors of the housing and utilities infrastructure enterprises economical security results in the necessity of application of the different methods of assessment of the degree of their influence, including expert ones. The necessity of development of the universal mathematical algorithms for determining the level of economic security, which liquidate inescapable subjectivity of expert evaluations and aspiration to build an efficient and effective mechanism to ensure the security of the enterprise determines the relevance of the selected research and determines the relevance of the selected research topic in the context of business practices [1].

\section{Methods}

Issues on economic security of economic entities are still not clearly understood by the native economic science. Still there is no consensus about substance of economic security,

*Corresponding author: dikareva-va@,rambler.ru 
criteria and a method of its definition. Grouping of the approaches for determining the housing and utilities infrastructure enterprises economic security depending on the key characteristics of the term was performed on the basis of the existing theoretical range (fig. 1) $[2]$.

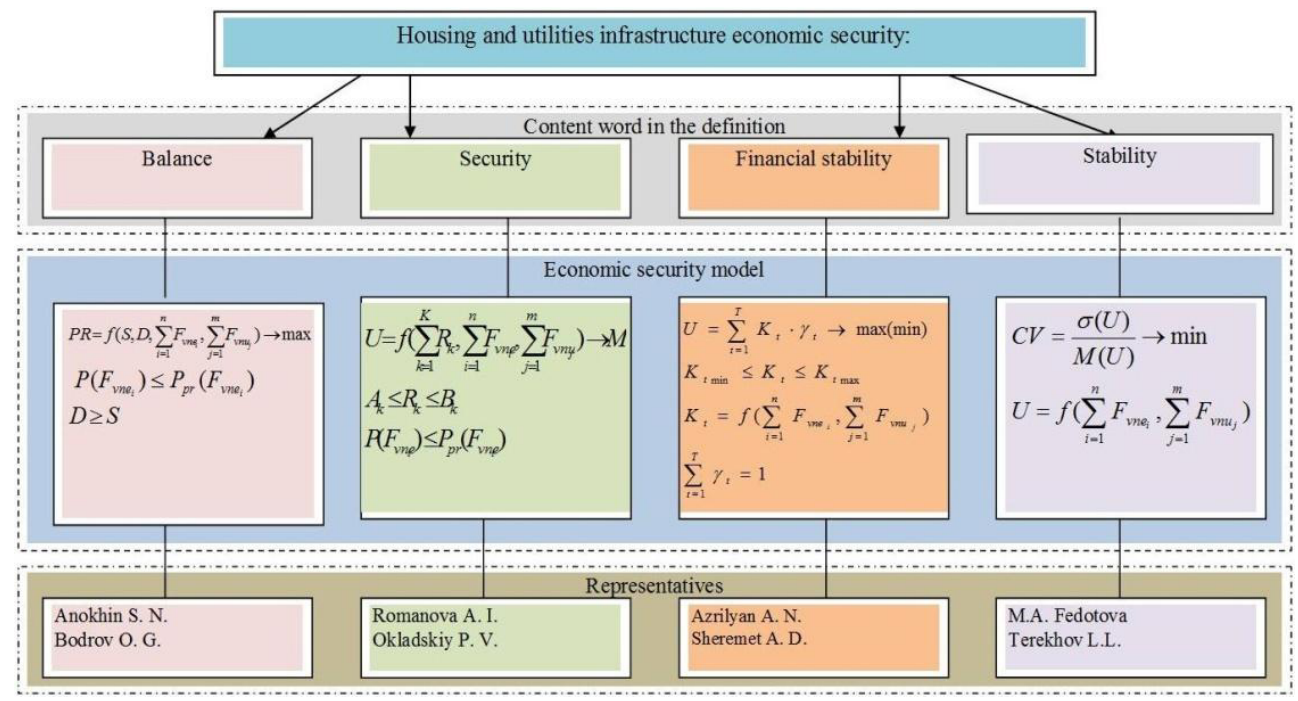

Fig. 1. Classification and modeling of existing approaches to the definition of the term of economic sustainability of the enterprise

where PR is the net profit of the enterprise, $\mathrm{S}$ is value of the product offering (works), D is value of the demand (work), Fvnt is factors of the external environment, Fvnu is factors of the external environment, $P(F)$ is the probability of the action of the factor, Ppr $(F)$ is predictive probability of the action of the factor, $\mathrm{R}$ is resources, A,B is resource limitation, $\mathrm{M}$ is the mission of the enterprise, $\mathrm{U}$ is economic security of the enterprise, $\mathrm{K}$ is financial ratios, $\gamma$ is the part of influence of the financial ratio on the overall performance, $M(U)$ is the mathematical expectation of stability, $\sigma$ is the mean-square deviation.

Stability is shown in the course of counteraction of the enterprise to negative external and internal factors, its reaction to the external and internal indignations, which bring it out of balance.

Economic and statistical models of the form were received for designation of the numerical value of the criteria:

$$
\mathrm{U}=\mathrm{f}\left({ }_{\mathrm{Fi}}\right), \mathrm{i}=\overline{1, n}
$$

Selection of the key factors is performed by the criteria of maximum dispersion and stability criteria (5-6 factors):

$$
\operatorname{Var}(U)=\sum_{i=1}^{n} p_{i} \cdot\left(U_{i}-M(U)\right)^{2} \rightarrow \max
$$

where $\mathrm{p}_{\mathrm{i}}$ is the probability of $\mathrm{U}_{\mathrm{i}}$ is value appearance, $M(U)$ is mathematical expectation of discrete random variable $U$.

3. Scenarios of key factors changing and their probabilities are defined. Cases of the most adverse changes in market factors, which have occurred in the past can be selected as a scenario. 
4. Numerical value of the criterion of stability is calculated for each scenario with accounting of its probability, as a result array of values and the mathematical expectation of stability:

$$
M(U)=\left\{M\left(U_{1}\right), M\left(U_{2}\right), \ldots M\left(U_{k}\right)\right\}
$$

5. Values of a variation factor on the basis of which it is concluded degree of stability of the building enterprise, and distribution function are defined. Functions of distribution (probability) determine probability of that random variable will be set to less than or equal to certain value.

$$
C V=\frac{\sigma(U)}{M(U)}
$$

At financial stability determination one of the main tasks is assessment of total ability to risk in the conditions of changing external environment. Under ability to risk should be understood the ability of housing and utilities infrastructure enterprises to withstand the effects of the risk events without losses of financial stability. To ensure this, there must be considered not only specific risks of the concrete project, but common risks of the enterprise, which can be attributed to the cost of production as a risk fee [3].

The process of determining risk fee can be divided into two progressive stages: gradual risks aggregation "from bottom to top" from the level of separate projects to the designoriented enterprise in general and transfer of value of the predicted risks on the unit of production $[4,5]$.Ability of enterprises of the construction industry to risk is determined by combination of available resources and risk coverage which provide it the financial stability. Various sources of risk financing are differing in their size, recovery rate, rules of use and impact on operating activity $[6,7]$. It leads to the necessity of structuring of the risk coverage recourses starting out from the quality of recourses, characterized by the impact on the organizations activity. Based on the above, it is necessary to allocate 5 classes of resources of the risks coverage (table 1).

Table 1. Structure of the risk pooling resources of the enterprise

\begin{tabular}{|l|l|l|}
\hline $\begin{array}{l}\text { Class of the risk } \\
\text { pooling resources }\end{array}$ & \multicolumn{1}{|c|}{ Payment instruments types } & \multicolumn{1}{|c|}{ Quality of the using resource } \\
\hline $\begin{array}{l}\text { First class } \\
\text { resources (RK1) }\end{array}$ & $\begin{array}{l}\text { Expected risk expenses for the } \\
\text { project or activity; } \\
\text { Cross financing of the laid risk } \\
\text { expenses of different projects }\end{array}$ & $\begin{array}{l}\text { Financial resources. Slight impact on } \\
\text { the activity of the organization and cash } \\
\text { flow. In case of use of resources of } \\
\text { future risks they are capable to cause } \\
\text { short-term crisis of solvency. }\end{array}$ \\
\hline $\begin{array}{l}\text { Second class } \\
\text { resources (RK2) }\end{array}$ & $\begin{array}{l}\text { Surplus profit of the project; } \\
\text { Expected profit of the project; }\end{array}$ & $\begin{array}{l}\text { Financial resources. Exert average } \\
\text { impact on the planned cash flow in case } \\
\text { of the local origin. Introduce the } \\
\text { necessity of revision of the short-term } \\
\text { and medium-term objectives of the } \\
\text { organization and norms of regulation. }\end{array}$ \\
\hline $\begin{array}{l}\text { Third class } \\
\text { resources (RK3) }\end{array}$ & $\begin{array}{l}\text { Liquidity Stocks; } \\
\text { Attraction of the share capital or } \\
\text { other forms of contributions by } \\
\text { the owners of the enterprise; } \\
\text { Easy fluid assets;Credit lines } \\
\text { Amortization charges }\end{array}$ & $\begin{array}{l}\text { Financial and property resources. Exert } \\
\text { average impact on the planned cash } \\
\text { flow in case of the private projects. Use } \\
\text { short-term solvency to eliminate crisis. }\end{array}$ \\
\hline $\begin{array}{l}\text { Fourth class } \\
\text { resources (RK4) }\end{array}$ & $\begin{array}{l}\text {-Hidden reserves, released } \\
\text { through the expenses on the non- } \\
\text { productive areas of activity; }\end{array}$ & $\begin{array}{l}\text { Financial and property resources. Exert } \\
\text { critical impact on all financial metrics, } \\
\text { production potential and competitive }\end{array}$ \\
\hline
\end{tabular}




\begin{tabular}{|l|l|l|}
\hline & $\begin{array}{l}\text { Passed obligations of operation of } \\
\text { the shareholders' dividends } \\
\text { Attraction of the paid-in capital at } \\
\text { the expense of capital issuance } \\
\text { Means from the sale of medium } \\
\text { and little fluid assets or } \\
\text { cancellation of investing activities } \\
\text { Reserve Fund }\end{array}$ & $\begin{array}{l}\text { advantages of the enterprise. In case of } \\
\text { threat of the formation of excess debt } \\
\text { are attracted. Review of the strategic } \\
\text { planning and optimization of } \\
\text { organizational structure is required. }\end{array}$ \\
\hline $\begin{array}{l}\text { Fifth class } \\
\text { resources (RK5) }\end{array}$ & $\begin{array}{l}\text { Means from the sales of } \\
\text { production capital funds and other } \\
\text { low-fluid assets; } \\
\text { Statutory fund }\end{array}$ & $\begin{array}{l}\text { Property resources. Attracted in the case } \\
\text { of insolvency and the excess debt } \\
\text { indicate on the pre-bankrupt or } \\
\text { bankrupt status of the enterprise. }\end{array}$ \\
\hline
\end{tabular}

Because of the fact that it's necessary to consider dynamic character of cost of resources of a covering and change of their possible release speed, it's necessary to develop calculated estimation model which is based on financial statements of the enterprise.

\section{Results}

Building of the estimation model is based on the following limitations:

1. Risk coverage resources (assets) formation occurs due to sources, repayment time of which is higher or equal the time required to turn the asset into the funds

2. The main balance sheet identity is respected: assets are equal to liabilities;

3. The lower fluid of the asset, the higher the importance of its coverage at the expense of proper and equivalent to it capital;

4. Financial sound organization is solvent organization;

5. Comparison of degrees of the financial stability of organization is incorrect without usage of regulatory, but not estimated coefficients of importance;

Determination of severities of model is proposed to calculate on the basis of connection of involvement of sources of the financial resources in the main activity by the degree of urgency of their maturity and assets according to their fluid from the least to the most urgent/fluid [8]. And severity that will be higher, than the asset sum which needs to be provided is lower. Assessment of the severity of the design ratio inclusive of provided above dependency on summing the assets it will be in interval from zero to one, but on grounds of the degree of importance of the design ratios, they placed from one to zero. It's necessary to subtract the share of units of the relevant assets in negotiable assets of the organization from one [9]. Common formula looks as follows:

$$
Y_{n}=1-\frac{\left(A_{1}+\ldots+A_{i}\right)}{A}
$$

Where: $\left(A_{1}+\ldots+A_{i}\right)$ - is the sum of (i)'s assets; A - the sum of all assets (Assets).

The estimated coefficients are determined on the basis of the common methods of determination of the type of financial stability [6], which provides their continuity and nonconflictness. Common formula of the design ratio looks as follows:

$$
X_{n}=\frac{\left(S_{1}+\ldots+S_{i}\right)-P}{A}
$$

Where: $X_{n}$ - is the design ratio; $\left(S_{1}+\ldots+S_{i}\right)$ is the sum of $(i)$ 's sources; $\mathrm{P}$ is a manufacturing portion of the assets. 
Thus, the estimated model of the assessment of the extent of the financial stability of construction companies will look as follows:

$$
Z=Y_{1} X_{1}+Y_{2} X_{2}+Y_{3} X_{3}+Y_{4} X_{4}+X_{5}
$$

Where: ${ }_{\mathrm{Y} 1}$ is the difference between the unit and the proportion of hardly fluid assets in total balance; ${ }_{\mathrm{Y} 2}$ is the difference between the unit and the sum of the shares of hardly fluid and slowly fluid assets in total balance; ${ }_{\mathrm{Y} 3}$ is the difference between the unit and the amount of shares of hardly fluid, slowly fluid and fast-fluid assets in total balance; Y4 is the difference between the unit and the amount of shares of hardly fluid, slowly fluid, fast-fluid and absolutely fluid assets in the currency of balance $=1$; $x_{1}$ is the ratio of the difference between shareholders' interests and fixed assets to the total balance; $\mathrm{x}_{2}$ is the ratio of the difference between working capital and holding and expenses to the total balance; $\mathrm{x}_{3}$ is the ratio of the difference between proper and long-term borrowing costs and reserves and expenses to the total balance; $\mathrm{x}_{4}$ is an attitude of the difference between the total value of the main sources of formation of reserves and expenses by the reserves and expenses to the total balance; $x_{5}$ is calculated as the ratio of the difference between the total value of the main sources of formation of reserves and expenses and loan payable, deferred credits, estimated liabilities, other liabilities and reserves and expenses to the total balance.

$\mathrm{Z}$-value is in the range from 0 to 1 depending on the degree of financial stability, multiplying it on $100 \%$, we draw the interest of financial stability from 0 to $100 \%$. In the presented model causes a problem of correlation of degree and type of financial stability. We offer the following payment intervals to determine the type of financial sustainability to resolve this problem $\mathrm{T}_{1}, \mathrm{~T} 2, \mathrm{~T} 3$, $\mathrm{T} 4$, (fig. 2.)Interval $\left.{ }_{\mathrm{T} 1}\right)=$ Crisis financial circumstances is defined as loan payable interest, deferred income, estimated liabilities and other liabilities in the total balance.

If $\mathrm{Z}$ is in the interval $\left[0 \%\right.$; 1 ; Interval $\left(_{\mathrm{T} 2}\right)=$ fragile financial condition is defined as the sum of the ${ }_{n 1}$ and interest of short-term loans and loans in the total balance. If $Z$ is in the interval $\left[{ }_{n 1} ;{ }_{n 2}\right]$; Interval $\left({ }_{\mathrm{T} 3}\right)=$ normal financial circumstances is defined as the sum of ${ }_{\mathrm{n} 2}$ and percent of the long-term liabilities in the total balance. If $\mathrm{Z}$ is in the interval $\left[\mathrm{n}_{1} ;{ }_{\mathrm{n} 2}\right]$; Interval $\left.{ }_{\mathrm{T} 4}\right)=$ absolute financial circumstances is defined as sum of the ${ }_{n} 3$ and percent of working capital in the total balance. If $\mathrm{Z}$ is in the interval $\left[\mathrm{n}_{3 \mathrm{n}}\right]$ ]. Intervals presented above are correct if working capital (working capital) $>0$ and current fluid ratio (current ratio) $>1$.

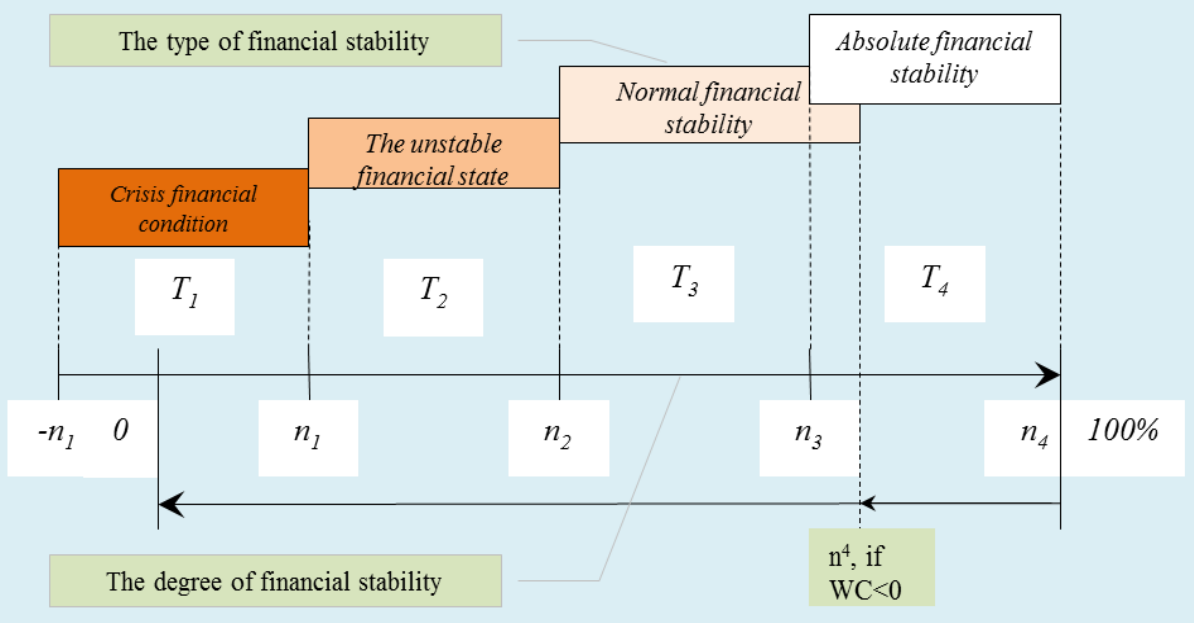

Fig. 2. Scale of the interpretation of observed data 


\section{Discussions}

If the current fluidity ratio is less than 1 , then all working and part of the non-working assets are funded at the expense of short-term liabilities. If working capital is not covered by short- term loans and credits then degree of financial stability of the construction companies will be negative amid a crisis of financial condition. These observations stem from the balance sheet identity and do not contradict with methods of determination of the type of financial stability.

\section{Conclusion}

Theoretical and methodical aspects on ensuring of economic stability of construction companies and projects presented in this article combine economic approaches along with usage of the simple but reliable mathematical apparatus. Application of the proposed methods based on the concept of blending aggregate risk pressures on limited coverage resources allows to assess objectively the degree of economic stability and identify overarching risk factors for the enterprise and to optimize the "expenses-effect" correlation when carrying out activities on enhancement of economic stability.

\section{References}

1. N.Y. Yaskova,D.N. Silka, V.S. Kankhva, I.G. Lukmanova.Finance and credit in construction. College textbook for the students. Moscow(2011)

2. I.G. Lukmanova, A.G. Korolev, E.V. Nezhnikova.Projects management. Study guide. Moscow (2013)

3. D.N. Silka, N.V.Scherbakova.Bulletin of the University 32. 204-209 (2009)

4. N.Y. Yaskova, D.N. Silka.Development of the investment and construction processes in the conditions of globalization, MGSU,Moscow(2011)

5. S.S. Uvarova, S.V. Belyaeva, S.V. Kankhva.Economic stability of the construction companies and projects, MGSU,Moscow(2013)

6. V.S. Kankhva,B.L. Efremjan, Scientific review, 12, 295-299, (2015)

7. B.Hirtle, A.Kovner, J. Vickery, M.Bhanot. Journal of Banking \& Finance, 69 (1), 35 55(2016)

8. J. Creel, P. Hubert, F.Labondance. Economic Modelling, 48, 25-40(2015)

9. P-R.Agénor, L. Pereira da Silva. Journal of Financial Stability, 28, 143-162(2017) 